\title{
5-Azacitidine induces demethylation of PTPL1 and inhibits growth in non-Hodgkin lymphoma
}

\author{
WENMING WANG ${ }^{1}$, JING WANG $^{1}$, MIN LI $^{2}$, JIANMING YING $^{3}$ and HONGMEI JING ${ }^{1}$ \\ Departments of ${ }^{1}$ Hematology and ${ }^{2}$ Pathology, Peking University Third Hospital, Beijing 100191; ${ }^{3}$ Department of Pathology, \\ Cancer Institute and Hospital, Chinese Academy of Medical Sciences, Beijing 100021, P.R. China
}

Received January 19, 2015; Accepted June 25, 2015

DOI: 10.3892/ijmm.2015.2269

\begin{abstract}
Non-Hodgkin lymphoma (NHL) consists of various lymphoid malignancies with a diverse clinical pathology and biological characteristics. Methylation of cytosine residues by DNA methyltransferases at $\mathrm{CpG}$ dinucleotides in the promoter region of the genes is a major epigenetic modification in mammalian genomes that can have profound effects on gene expression. The PTPL1 methylation pattern was screened by methylation-specific polymerase chain reaction (MSP) in 7 lymphoma-derived cell lines and in 47 samples of diffuse large B cell lymphoma (DLBCL). The PTPL1 gene was hypermethylated in the CA46, Raji, Jurkat and DB cell lines; however, it was unmethylated in the Hut78, Maver and Z138 cell lines. The expression of PTPL1 mRNA was re-inducible by 5-azacytidine (5-Aza), an agent of DNA demethylation. The methylations were detected in $59.6 \%$ of DLBCL versus $6.3 \%$ in reactive lymph node proliferation. Therefore, the present data showed that PTPL1 was epigenetically regulated in NHL suggesting an involvement of the PTPL1 tumor-suppressor genes in NHL, and highlights 5-Aza as a potential therapeutic candidate for NHL.
\end{abstract}

\section{Introduction}

Non-Hodgkin lymphoma (NHL) is a common hematological cancer with multiple subtypes, derived from various differentiation stages of the B cell lineage. Burkitt lymphoma (BL) is the most common NHL subtype (69\%), followed by lymphoblastic lymphoma, diffuse large B cell lymphoma (DLBCL) and anaplastic large-cell lymphoma, accounting for 18.3, 10.6 and $2.1 \%$ of the cases, respectively (1). Although high-dose multiagent chemotherapy and targeted agents induce high

Correspondence to: Dr Hongmei Jing, Department of Hematology, Peking University Third Hospital, No. 49 North Garden Road, Haidian, Beijing 100191, P.R. China

E-mail: jinghm@yahoo.com

Key words: PTPL1, mehthylation, lymphoma, diffuse large B-cell lymphoma, 5-azacytidine remission rates in patients with previously untreated NHL, relapse and drug resistance within a few years is common. Therefore, discovering new therapeutic agents for NHL is required (2).

Cancer cells develop acquiring a set of functional capabilities for malignant growth, such as self-sufficiency in growth signals, insensitivity to growth-inhibitory signals and evasion from apoptosis $(3,4)$. These essential alterations in cell physiology are achieved by the constitutive activation of oncogenes and the loss of function of the tumor-suppressor genes (5). Genetic and epigenetic mechanisms can all contribute to the inactivation of tumor-suppressor genes (6). Methylation of cytosine residues by DNA methyltransferases (DNMTs) at $\mathrm{CpG}$ dinucleotides in the promoter region of genes is a major epigenetic modification in mammalian genomes that can have profound effects on gene expression $(7,8)$. One study has shown that DNMTs, including DNMT1, DNMT3A and DNMT3B are overexpressed in 48, 13 and $45 \%$ of de novo DLBCLs, respectively, which correlates with advanced clinical stage (9). In addition, the therapeutic efficacy of the demethylating agents, such as decitabine and 5-azacytidine (5-Aza), can induce significant clinical responses and even prolong the survival of patients with higher-risk myelodysplastic syndrome (10).

PTPL1 maps to the human chromosomal locus $4 \mathrm{q} 21$, and encodes a cytoplasmic tyrosine phosphatase with a molecular mass of $270 \mathrm{kDa}$ with roles in numerous physiological and pathological processes. Among the potential roles in carcinogenesis, the PTPLl gene product can impact cancer development through its capacity to counteract the activity of oncogenic tyrosine kinases or its inhibitory interaction with the death receptor Fas (11). Several studies have shown that hypermethylation of the PTPL1 gene promoter is involved in various types of cancers, such as non-small cell lung cancer (11), esophageal cancer, gastric and hepatocellular tumors $(2,12)$.

The aim of the present study was to analyze PTPL1 methylation patterns in a broad spectrum of NHL-derived cell lines and de novo DLBCL samples. Epigenetic regulation of PTPL1 was confirmed in experiments with a DNA demethylating agent. The results obtained from the study significantly contribute towards an improved understanding of the role of PTPL1 as a tumor-suppressor gene in NHL, and 5-Aza may offer a potential new therapeutic approach to improve the poor outcomes associated with NHL. 


\section{Materials and methods}

\section{Human cell lines}

Cell culture. The study included 7 cell lines, Hut78 (cutaneous $\mathrm{T}$ cell lymphoma cell line), Maver, Z138 (mantle cell lymphoma cell lines), CA46, Raji (Burkitt lymphoma cell lines), Jurkat (acute $\mathrm{T}$ cell lymphoma cell line) and DB (DLBCL cell line). All the cell lines, except CA46, were maintained in RPMI-1640 supplemented with $10 \%$ fetal bovine serum (FBS) (HyClone, Logan, UT, USA) and 1\% antibiotics (Gibco-Invitrogen, Carlsbad, CA, USA). CA46 was maintained with RPMI-1640 supplemented with 20\% FBS (HyClone) and 1\% antibiotics (Gibco-Invitrogen). Cells were incubated at $37^{\circ} \mathrm{C}$ in a humid atmosphere at $5 \% \mathrm{CO}_{2}$ and split every 2-3 days depending on cell density.

In vitro cytotoxicity assays. Raji and Jurkat cells in the logarithmic growth phase were inoculated in a 96-well plate, with $100 \mu \mathrm{l} /$ well and a cell suspension density of $2.5 \times 10^{5} / \mathrm{ml}$. The cells were randomly divided into the control and test groups medially with 4 duplicates/group. They were subsequently treated with 5-Aza at 0.1, 0.5, 1, 2, 5, 10, 20 and $50 \mu \mathrm{mol} / 1$ for 24,48 and $72 \mathrm{~h}$, respectively. CCK- 8 (10 $\mu \mathrm{l}$; Dojindo, Kumamoto, Japan) accompanied every sampling in each well. After $2 \mathrm{~h}$ of incubation, the absorption value (A) of each well was detected at the wavelength of $450 \mathrm{~nm}$ in a Quant spectrophotometer. Drug-free wells were used as a control and the no-cell wells with the same amounts of 5-Aza were used as blank controls. Cell inhibition rate (I\%) was calculated using the following equation: $\mathrm{I} \%=[\mathrm{A}($ control $)-\mathrm{A}($ treated $) / \mathrm{A}(\mathrm{control})-\mathrm{A}($ blank $)] \times 100 \%$

Treatment with 5-Aza. 5-Aza dissolved in normal saline was used to verify the effect on PTPL1 expression. Three cells lines (CA46, Raji and Jurkat) were seeded at a density of $2.5 \times 10^{5}$ cells $/ \mathrm{ml}$ and $5-\mathrm{Aza}$ was added at a final concentration of $20 \mu \mathrm{mol} / 1$ for CA46, $15 \mu \mathrm{mol} / 1$ for Raji and $3.5 \mu \mathrm{mol} / 1$ for Jurkat. Cells were randomly assigned into 3 groups: Negative control group (added in normal saline), 5-Aza-24 h group (treated with 5-Aza for $24 \mathrm{~h}$ ) and 5-Aza-48 h group (treated with 5-Aza-Cdr for $48 \mathrm{~h}$ ). Cells were harvested, respectively, to prepare DNA and RNA.

DNA extraction and bisulfite conversion. Genomic DNA was extracted by the E.Z.N.A ${ }^{\circledR}$ Tissue DNA kit (Omega Bio-Tek, Lilburn, GA, USA). DNA (200 ng) in a volume of 1-5 $\mu \mathrm{l}$ and was subjected to treatment with sodium bisulfite using a CpGenome DNA modification kit (Epigentek, Farmingdale, NY, USA), according to the manufacturer's instructions. Modified DNA was stored at $-80^{\circ} \mathrm{C}$ until use.

Methylation-specific polymerase chain reaction (MSP). Modified DNA was subjected to two separate PCRs. MSP primers were designed to amplify the methylated or unmethylated alleles, and the Methylamp Universal Methylated DNA kit (Epigentek) was used as a positive control. Promoter methylation status was analyzed by MSP using methylated and unmethylated gene-specific primers for PTPL1 (12). Primers for PTPL1 were 5'-CGAGTAGTTTTA GCGGTTAC-3' (sense) and 5'-AAAACCTTCTAACGCGAA CGA-3' (antisense) for the methylated reaction and 5'-TGTGAG TAGTTTTAGTGGTTAT-3' (sense) and 5'-CAAAACCTT CTAACACAAACAA-3' (antisense) for the unmethylated reaction. These primer sets were designed to amplify 160 and
$163 \mathrm{bp}$, respectively. The methylation promoter was: $95^{\circ} \mathrm{C}$ for $5 \mathrm{~min}$; 40 cycles of $95^{\circ} \mathrm{C}$ for $50 \mathrm{sec}, 58^{\circ} \mathrm{C}$ for $1 \mathrm{~min}$ and $72^{\circ} \mathrm{C}$ for $1 \mathrm{~min}$; and a final extension at $72^{\circ} \mathrm{C}$ for $10 \mathrm{~min}$; the unmethylation promoter was: $95^{\circ} \mathrm{C}$ for $5 \mathrm{~min}$; 40 cycles of $95^{\circ} \mathrm{C}$ for $50 \mathrm{sec}, 60^{\circ} \mathrm{C}$ for $1 \mathrm{~min}$ and $72^{\circ} \mathrm{C}$ for $1 \mathrm{~min}$; and a final extension at $72^{\circ} \mathrm{C}$ for $10 \mathrm{~min}$. Amplified products were visualized under an ultraviolet gel imaging system using the GeneSnap System (Multi Genius; Syngene, Cambridge, UK) following electrophoresis in 2\% agarose gels containing the GelRed Nucleic Acid Gel Stain. For each case, MSP results were scored when a clearly visible band on the electrophoresis gel with the methylated and/or the unmethylatated primers were observed. Results from triplicate experiments were used to determine methylation status.

RNA isolation and reverse transcription-polymerase chain reaction $(P C R)$. RNA was isolated using TRIzol (Gibco-Invitrogen), according to the manufacturer's instructions. Total cellular RNA $(1 \mu \mathrm{g})$ was reverse transcribed using the GoScript ${ }^{\mathrm{TM}}$ Reverse Transcription system (Promega, Madison, WI, USA). Primers were: PTPL1 forward, 5'-GCG CTCCAGTAGCAGGAC-3' and reverse, 5'-TCATCTGTA AATGACACACTAC-3'; and glyceraldehyde 3-phosphate dehydrogenase (GAPDH; as a control) forward, 5'-GGAGCG AGATCCCTCCAAAAT-3' and reverse, 5'-GGCTGTTGT CATACTTCTCATGG-3'. Amplified products were visualized under an ultraviolet gel imaging system using the GeneSnap System (Multi Genius; Syngene) following electrophoresis in $2 \%$ agarose gels containing a GelRed Nucleic Acid Gel Stain.

Western blot analysis. Protein was extracted from Hut78, Maver, Z138, CA46, Raji, Jurkat and DB cell lines. Protein concentrations of cells were determined using a bicinchoninic acid protein assay kit (Applygen Technologies Inc., Beijing, China). Western blot analyses were performed using the following primary antibodies: Anti-PTPL1 (1:200; sc-15356) and anti- $\beta$-actin $(1: 1,000$; sc-130656) (both from Santa Cruz Biotechnology, Inc., Dallas, TX, USA). Lysates (60 $\mu \mathrm{g})$ were resolved on sodium dodecyl sulfate-polyacrylamide gel electrophoresis gels (PTPL1 8\% and $\beta$-actin 10\%) and transferred to NC membranes. Membranes were blocked with $5 \%$ bovine serum albumin in Tris-buffered saline and Tween 20 and primary antibodies (Abs) were added overnight. Fluorescently labeled secondary antibodies $(1: 10,000)$ were used and the membranes were scanned using the Odyssey Infrared Imaging system (both from LI-COR Biosciences, Lincoln, NE, USA).

\section{Patients}

Patient selection. The formalin-fixed paraffin-embedded (FFPE) tissues of 47 DLBCL patients and 16 reactive lymph nodes (as control) were evaluated. The archived FFPE tissues were obtained from the Department of Pathology, Peking University Third Hospital (Beijing, China). The patients were diagnosed according to the criteria of the 2008 World Health Organization classification and were clinically staged according to the Ann Arbor classification. Clinical outcomes were evaluated according to the standard international criteria.

DNA extraction, bisulfite conversion and MSP. Genomic DNA of 47 patient samples and 16 reactive lymph nodes were extracted using the E.Z.N.A ${ }^{\circledR}$ FFPE DNA kit (Omega Bio-Tek). DNA (200 ng) in a volume of 1-5 $\mu$ l was subjected to treatment with sodium bisulfite using a CpGenome DNA modification 
kit (Epigentek). The reaction system and reaction conditions of MSP were the same as the experimental cell lines.

Statistical analysis. Statistical analyses were carried out with Social Sciences software (SPSS, version 20.0; IBM Corp., Armonk, NY, USA). Pairwise correlations between the methylation status of DLBCL and control patients, and the germinal center phenotype (GCB) and non-GCB patients were investigated by $\chi^{2}$ test or Fisher's exact test where appropriate. Statistical significance was set at the two-sided 5\% comparison wise. $\mathrm{P}<0.05$ was considered to indicate a statistically significant difference.

\section{Results}

\section{Human cell lines}

Analysis of PTPL1 gene methylation in lymphoma cell lines. The PTPL1 methylation pattern was analyzed by MSP. Following bisulfite conversion of DNA, the methylation status of PTPL1 was determined with MSP in the lymphoma cell lines. According to MSP, PTPL1 was methylated in the CA46, Raji, Jurkat and DB cell lines and unmethylated in the Hut78, Maver and Z138 cell lines (Fig. 1).

PTPL1 mRNA expression in lymphoma cell lines. To evaluate the correlation between methylation of the PTPL1 and PTPL1 transcription, reverse transcription PCR was performed with cDNA from the lymphoma cell lines. The expression of PTPL1 mRNA was ubiquitously expressed at different levels in Hut78, Maver and Z138 cells, but silenced in CA46, Raji, Jurkat and DB cells (Fig. 2).

PTPL1 protein expression in lymphoma cell lines. Further examination was performed on the PTPL1 protein. The expression of the PTPL1 protein was ubiquitously expressed at different levels in Hut78, Maver and Z138 cells, but silenced in CA46, Raji, Jurkat and DB cells (Fig. 3). In the majority of the lymphoma cell lines, $P T P L 1$ gene expression was inversely correlated with PTPLI hypermethylation. This suggests that $P T P L 1$ is regulated by DNA methylation in lymphoma cells.

5-Aza induces growth inhibition of Raji and Jurkat cells lines. Cell proliferation was detected using the CCK8 kit after 12, 24, 48 and $72 \mathrm{~h}$ treatment (Fig. 4). 5-Aza inhibited the proliferation of Raji and Jurkat cells in a concentration-dependent manner. Patterns of the inhibition efficiency differ in different cell lines.

Restoration of PTPL1 gene expression by 5-Aza, a DNMTs inhibitor. PTPL1 re-expression was investigated following treatment of CA46, Raji and Jurkat cells lines with the DNMTs inhibitor 5-Aza. 5-Aza treatment increased PTPL1 mRNA expression compared to the untreated control in the cell lines. In CA46, Raji and Jurkat cells, treatment with 5-Aza lead to re-expression of PTPL1 at $48 \mathrm{~h}$ (Fig. 5). The final half inhibitory concentrations were $20 \mu \mathrm{M}$ for CA46, $15 \mu \mathrm{M}$ for Raji and $3.5 \mu \mathrm{M}$ for Jurkat, respectively.

\section{Patients}

Patient characteristics. Forty-seven samples were screened and 23 samples were followed up. Among the 23 follow-up patients, there were 11 males and 12 females, with a median age of 63 years (range, 26-81 years). Of the 23 patients,

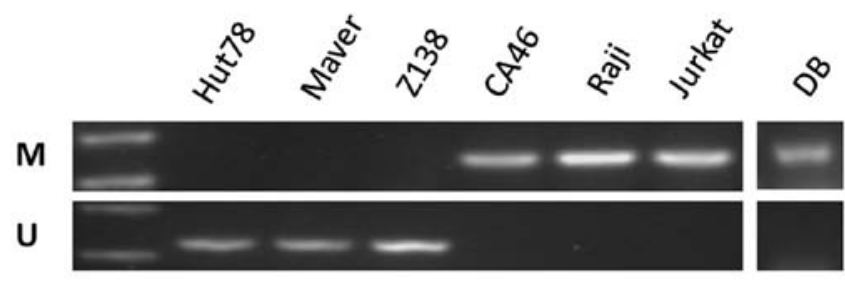

Figure 1. Representative analyses of the methylation of PTPL1 in multiple lymphoma cell lines. M, methylated; U, unmethylated; Hut78, cutaneous T cell lymphoma; Maver and Z138, mantle lymphoma; CA46 and Raji, Burkitt's lymphoma; Jurkat, acute T cell lymphoma cell line; DB, diffuse large B cell lymphoma.

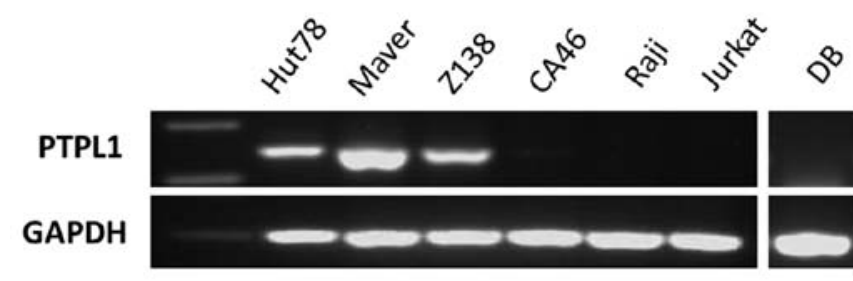

Figure 2. Expression of PTPL1 mRNA in lymphoma cell lines. PTPL1 mRNA expression was detected by semi-quantitative reverse transcription-polymerase chain reaction, with $G A P D H$ as a control. The expression of PTPL1 mRNA was ubiquitously expressed at different levels in Hut78, Maver and Z138 cells, but silenced in CA46, Raji, Jurkat and DB cells.

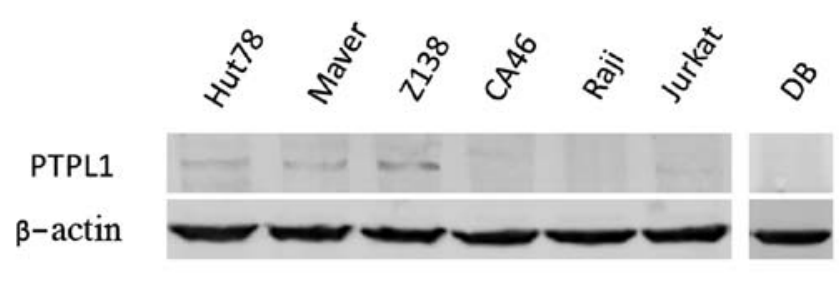

Figure 3. Western blott analysis of the PTPL1 protein in Hut78, Maver, Z138, CA46, Raji, Jurkat and DB cell lines, with $\beta$-actin as a control. The PTPL1 protein was ubiquitously expressed at different levels in Hut78, Maver and Z138 cells, but silenced in CA46, Raji, Jurkat and DB cells.

$5(21.7 \%)$ were stage I, 6 (26.1\%) were stage II, $2(8.7 \%)$ were stage III, and 10 (43.5\%) were stage IV. Using the Hans classification model, 9 cases were GCB and 14 were non-GCB, with a GCB:non-GCB ratio of 1:1.5 (Table I).

Promoter methylation status of DLBCL and reactive lymph node patients. Among the 47 DLBCL cases, the promoter of gene PTPL1 was methylated in $59.6 \%$ (28/47) (Fig. 6), and unmethylated in $40.4 \%$ (19/47) (Table II).

In 9 GCB patients, the promoter of the PTPLI gene was methylated in $22.2 \%(2 / 9)$ and unmethylated in $77.8 \%$ (7/9). In the 14 non-GCB patients, the promoter of PTPL1 was methylated in $64.3 \%(9 / 14)$ and unmethylated in $35.7 \%(5 / 14)$ (Table III). In the 16 reaction lymph node cases, the frequency of methylation was $6.3 \%(1 / 16)$, and the frequency of unmethylation was $93.8 \%(15 / 16)$.

Statistical analysis. The Fisher exact probability method was used to evaluate the difference of the number of methylated PTPL1 promoters between DLBCL patients and reactive lymph node cases, GCB group and non-GCB group. The difference of 
A

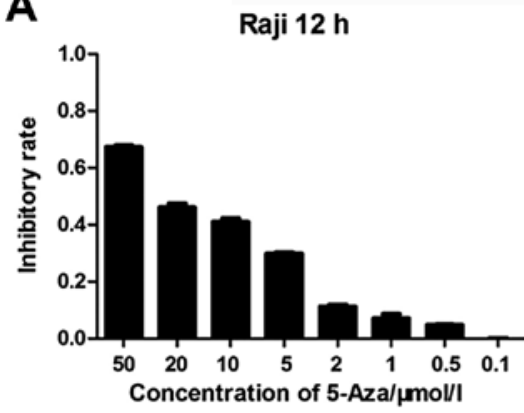

Raji $48 \mathrm{~h}$

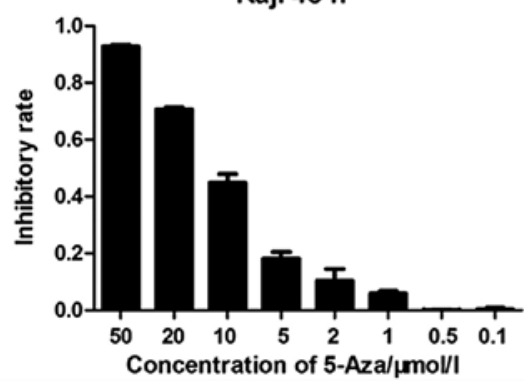

B

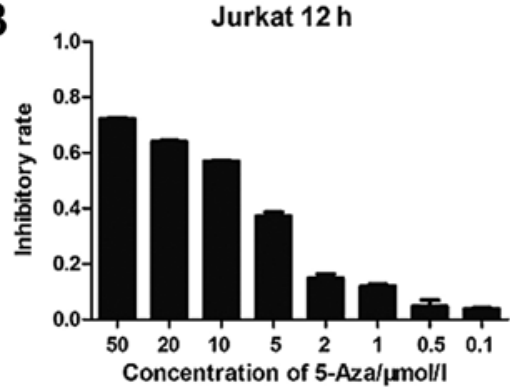

Jurkat $48 \mathrm{~h}$

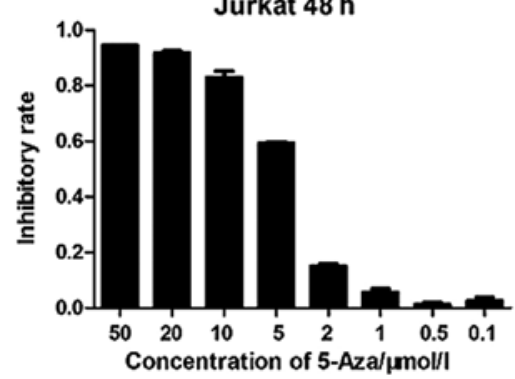

Raji $24 \mathrm{~h}$

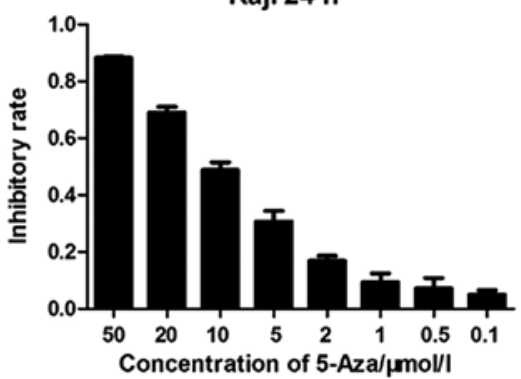

Raji $72 \mathrm{~h}$

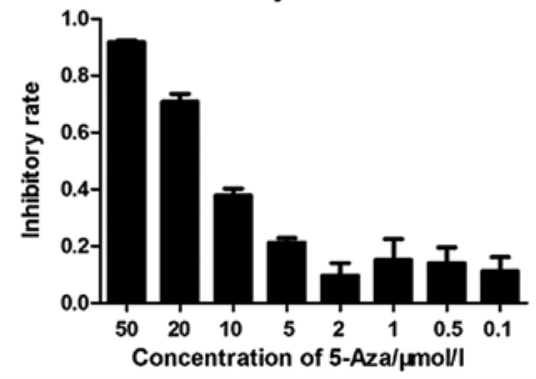

Jurkat $24 \mathrm{~h}$

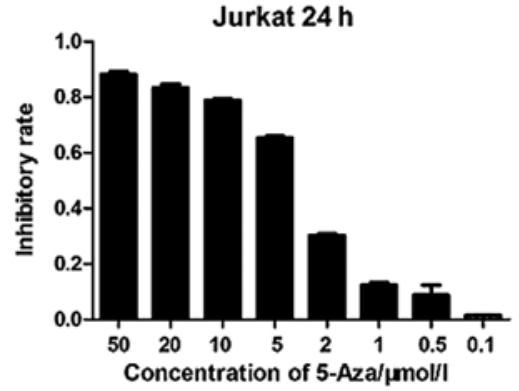

Jurkat $72 \mathrm{~h}$

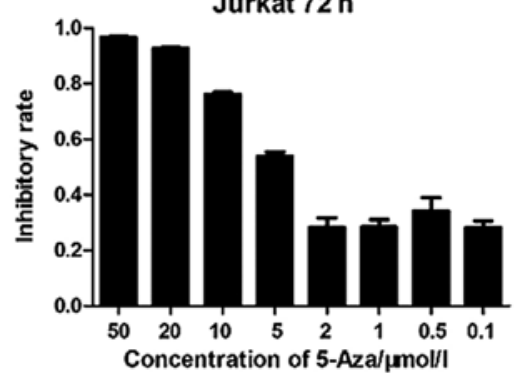

Figure 4. 5-Azacytidine (5-Aza) induces growth inhibition of (A) Raji and (B) Jurkat cells lines.

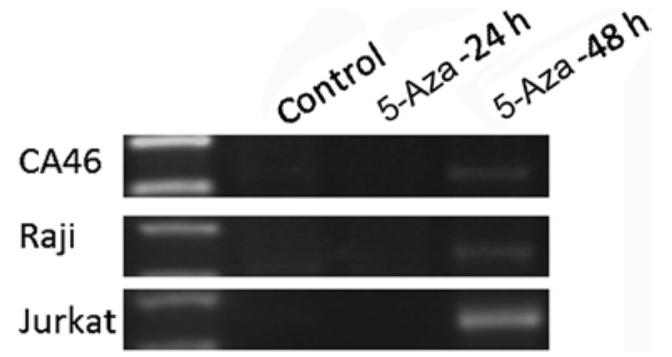

Figure 5. Restoration of PTPL1 gene expression by 5-azacytidine (5-Aza). 5-Aza induced the re-expression of the PTPL1. Re-expression of PTPL1 was observed after $48 \mathrm{~h}$ of treatment with 5-Aza.

the number of methylated PTPL1 promoters between DLBCL patients and reactive lymph node proliferation cases was statistically significant $(\mathrm{P}<0.001)$. The difference of the number of
$\mathrm{M}$

u

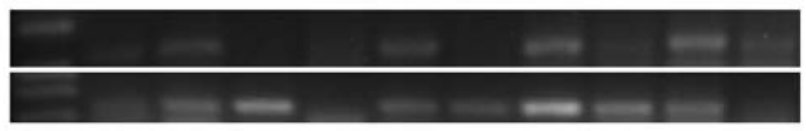

Figure 6. Methylation pattern of PTPL1 in diffuse large B cell lymphoma patients.

methylated PTPL1 promoters between the GCB and non-GCB group was not statistically significant $(\mathrm{P}=0.089)$.

\section{Discussion}

The aim of the present study was to identify novel methylated biomarkers in lymphoma and to explore potential new therapeutic targets. The methylation pattern of the PTPL1 
Table I. Clinical characteristics of 23 patients with DLBCL.

\begin{tabular}{lc}
\hline Clinical characteristic & Patients, $\mathrm{n}(\%)$ \\
\hline Gender & \\
Male & $11(47.8)$ \\
Female & $12(52.2)$ \\
Age, years & \\
$<65$ & $15(65.2)$ \\
$\geq 65$ & $8(34.8)$ \\
Stage & \\
I & $5(21.7)$ \\
II & $6(26.1)$ \\
III & $2(8.7)$ \\
IV & $10(43.5)$ \\
Type & \\
GCB & $9(39.1)$ \\
Non-GCB & $14(61.9)$ \\
\hline
\end{tabular}

DLBCL, diffuse large B cell lymphoma; GCB, germinal center phenotype.

Table II. PTPL1 methylation pattern in DLBCL patients.

\begin{tabular}{lcc}
\hline Patients & Methylated, n(\%) & Unmethylated, n (\%) \\
\hline DLBCL, $\mathrm{n}=47$ & $28(59.6)$ & $19(40.4)$ \\
Reactive lymph & $1(6.3)$ & $15(93.7)$ \\
nodes, $\mathrm{n}=16$ & & \\
\hline
\end{tabular}

Fisher's exact test $\mathrm{P}<0.001$. DLBCL, diffuse large $\mathrm{B}$ cell lymphoma.

Table III. PTPL1 methylation pattern in GCB and non-GCB patients.

\begin{tabular}{lcc}
\hline Patients & Methylated, $\mathrm{n}(\%)$ & Unmethylated, $\mathrm{n}(\%)$ \\
\hline GCB, $\mathrm{n}=9$ & $2(22.2)$ & $7(77.8)$ \\
Non-GCB, $\mathrm{n}=14$ & $9(64.3)$ & $5(35.7)$ \\
\hline
\end{tabular}

Fisher's exact test $\mathrm{P}=0.089$. DLBCL, diffuse large B cell lymphoma; $\mathrm{GCB}$, germinal center phenotype.

gene was investigated in certain lymphoma-derived cell lines and 47 DLBCL cases. PTPL1 was methylated in two Burkitt lymphoma cell lines (CA46 and Raji), one acute T cell lymphoma cell line (Jurkat) and one DLBCL cell line (DB); and unmethylated in the cutaneous $\mathrm{T}$ cell lymphoma cell line (Hut78), and in two mantle cell lymphoma cell lines (Maver and Z138). The methylated frequency of PTPL1 in DLBCL patients was significantly higher compared to the non-malignant lymphoid control. Shi et al (13) reported that there were significant differences in DNA methylation between pre-germinal and germinal center-derived NHL. In general, germinal center-related lymphomas (follicular lymphoma and DLBCL) have more methylation compared to non-germinal center lymphoma (mantle cell lymphoma and chronic lymphocytic leukemia/lymphoma) (14). The present study shows that the PTPL1 methylation frequency of non-GCB was higher compared with GCB. Clinically, the malignancy of non-GCB is higher compared with GCB, and prior to the appearance of rituximab, the prognosis of non-GCB was worse compared with GCB (15). Hypermethylation of the PTPL1 promoter was also identified in a small number of carcinomas, including gastric and hepatocellular tumors, with 8/12 hepatocellular tumors presenting with significant methylation patterns (16). In addition, the methylation pattern of several genes were identified in lymphoma, such as SHP1, CD44, DAPK, GSTP1, MGMT, P14, P15, P16, P33, RB1, hMLH1, CDH1, APC, RASSFA1, TIMP3, VHL and BLU (17-20). Epigenetic abnormalities affecting histone-modifying enzymes and regulators, such as histone deacetylases (HDACs), have also been described in lymphoma (21). The methylation of lysine 9 and lysine 27 of histone $\mathrm{H} 3$ (H3K9me and H3K27me) can lead to transcriptional repression of the target gene; however, the methylation of lysine 4 and lysine 36 of histone H3 (H3K4me and $\mathrm{H} 3 \mathrm{~K} 36 \mathrm{me}$ ) can lead to transcriptional activation of the target gene $(22,23)$. These all indicate that epigenetic alterations of gene expression are important in the development of tumorigenesis. The present study also confirmed this by showing that methylation of the promoter region of PTPL1 correlates with lymphoma.

In addition, the present study has detected PTPL 1 mRNA in cell lines. To compare this finding with the methylation patterns of the previously described cell lines, the expression of PTPL1 mRNA was ubiquitously expressed at different levels in the unmethylated cell lines (Hut78, Maver and Z138) and silenced in the total methylated cell lines (CA46, Raji, Jurkat and DB). Methylation of cytosine residues at $\mathrm{CpG}$ dinucleotides in the promoter region of genes is a major epigenetic modification in mammalian genomes and can lead to the silencing of gene expression $(24,25)$. Epigenetic regulation of PTPL1 expression was also documented in other cancers. In a study using a total of 82 tumor cell lines, Ying et al (26) showed that the expression of PTPL1 was frequently downregulated or silenced in NHL $(94 \%, 15 / 16)$, Hodgkin lymphoma $(50 \%, 3 / 6)$, breast $(30 \%, 3 / 10)$, gastric $(60 \%, 6 / 10)$ and hepatocellular $(67 \%, 8 / 12)$ carcinoma cell lines. In another study, Lee et al (27) identified that PTPL1 can be detected in $80 \%$ of hepatocellular carcinoma with a significant variation of the protein expression level by immunohistochemistry staining. The present findings indicate that this epigenetic alteration of PTPL1 is a common phenomenon in lymphoma and may be an important approach to inactivate cancer-related genes in this disease. However, these results also show that DNA methylation is not the only reason for PTPL1 silencing.

The PTPL1 re-expression pattern was also investigated following treatment with the DNMTs inhibitor 5-Aza to further confirm the role of DNA methylation in PTPL1 regulation. Re-expression of PTPL1 mRNA emerged at $48 \mathrm{~h}$ after treated with 5-Aza. 5-Aza exerts its action by inhibiting DNA methylation (via its incorporation into DNA at cytosine positions) during DNA replication. In general, their transport is mediated by the human concentrative nucleoside transporter 1 (hCNT1) 
followed by their phosphorylation and conversion into their active tri-phosphate forms, namely 5-Aza-CTP (28). In this way, 5-Aza is able to interact with DNMTs, inhibit their activity and decrease overall DNA methylation levels. Therefore, the effect of 5-Aza on cell lines may be associated with the activity or expression of DNMT1, DNMT3A and DNMT3B (29). Overall, these data suggest that the DNA methyltransferase inhibitor 5-Aza was able to successfully lead to re-expression of PTPL1 mRNA. The results confirmed that hypermethylation of PTPL1 was responsible for gene silencing, as DNA demethylation resulted in reactivation of $P T P L 1$ transcription in the PTPL1 hypermethylated cell lines. This may also support a tumor-suppressor role for PTPL1 in lymphoma.

By contrast, the relative increase of PTPL1 level in tumor tissues supports the role in tumor promotion. A high level of PTPL1 mRNA expression in Kaposi's sarcoma, hepatocellular carcinomas, pancreatic adenocarcinomas, as well as with higher expression in T helper cells type 1 (which are resistant to apoptosis) versus $\mathrm{T}$ helper cells type 2 (which are sensitive to Fas ligand), also shows a correlation between tumor cell survival in the presence of PTPL1 expression (11,30-32). In addition, investigators have shown relatively higher levels of PTPL1 expression in multiple carcinomas compared to the normal adjacent tissue as detected by immunohistochemistry (33). Another previous study showed that in the process of dimethyl sulfoxide- and all-trans retinoic acid-induced differentiation in HL-60 cells, the increased resistance to death receptor-mediated apoptosis coincided with an increase in PTPL1 (34). In CML, the resistance to death receptor-mediated apoptosis and the existence of leukemic stem cells were associated with an increase in PTPL1 (35). A positive correlation between PTPL1 expression and resistance to Fas-induced apoptosis has been shown in human T lymphotrophic virus (HTLV-I) infected $\mathrm{T}$ cell lines, ovarian cancer cell lines, human pancreatic cancer cell lines and squamous cell carcinomas of the head and neck cell lines (36). The presence of high PTPL1 levels in tumor tissues may oppose PTPL1 as a tumor suppressor. This may indicate that $P T P L 1$ has a role as a tumor promoter. The induction of PTPL1 by an oncogene and relative increase of PTPL1 levels in tumor tissues supports a role in tumor promotion. By contrast, epigenetic studies are more consistent with a role for PTPL1 as a tumor suppressor. The impact of PTPL1 on cancer is divided between its capacity to counteract the activity of oncogenic tyrosine kinases and its inhibitory interaction with the death receptor, Fas. The ability of PTPL1 to inhibit signaling from growth factor receptors or oncogenes with tyrosine kinase activity can suppress tumor occurrence $(37,38)$. By contrast, the ability of PTPL1 to interact with the Fas receptor can promote tumor occurrence (39). Therefore, according to the tissue type and the cellular environment, different proportions of these two signaling pathways can lead to different biological effects. A complete understanding of epigenetic modifications of PTPLI and various PTPLI domains in mediating protein-lipid and protein-protein interactions will be critical in resolving the functional role of PTPL1 in cancer. Establishing the precise function of PTPL1 in NHL and understanding its mode of action will aid in our understanding of the use of PTPL1 as a therapeutic target in NHL.

In the present study, the number of DLBCL cases was less, and that of subjects lost to follow-up was greater. More cases and future molecular studies are required to determine the role of PTPL1 methylation in the development and progression of NHL.

In conclusion, the study showed that PTPL1 expression is regulated by DNA methylation, not only in lymphoma cell lines, but also in the DLBCL patients. The loss of PTPL1 mRNA is the consequence of PTPLI methylation and can be reversed by 5-Aza. Thus, 5-Aza may be further investigated as a novel therapeutic agent for NHL.

\section{Acknowledgements}

The authors would like to thank Professor Junmin Li (Shanghai Ruijin Hospital, China) for the provision of the DB cell lines.

\section{References}

1. Sherief AM, Elsafy UR, Abdelkhalek ER, Kamal NM, Youssef DM and Elbehedy R: Disease patterns of pediatric non-Hodgkin lymphoma: A study from a developing area in Egypt. Mol Clin Oncol 3: 139-144, 2015.

2. Bradley WD, Arora S, Busby J, Balasubramanian S, Gehling VS, Nasveschuk CG, Vaswani RG, Yuan CC, Hatton C, Zhao F, et al: $\mathrm{EZH} 2$ inhibitor efficacy in non-Hodgkin's lymphoma does not require suppression of $\mathrm{H} 3 \mathrm{~K} 27$ monomethylation. Chem Biol 21: 1463-1475, 2014.

3. Miyazaki T, Atarashi Y, Yasumura S, Minatoya I, Ogawa K, Iwamoto M, Minemura M, Shimizu Y, Sato TA, Watanabe A, et al: Fas-associated phosphatase-1 promotes Fas-mediated apoptosis in human colon cancer cells: Novel function of FAP-1. J Gastroenterol Hepatol 21: 84-91, 2006.

4. Yeh SH, Wu DC, Tsai CY, Kuo TJ, Yu WC, Chang YS, Chen CL, Chang CF, Chen DS and Chen PJ: Genetic characterization of fas-associated phosphatase-1 as a putative tumor suppressor gene on chromosome 4q21.3 in hepatocellular carcinoma. Clin Cancer Res 12: 1097-1108, 2006.

5. Eberth S, Schneider B, Rosenwald A, Hartmann EM, Romani J, Zaborski M, Siebert R, Drexler HG and Quentmeier H: Epigenetic regulation of CD44 in Hodgkin and non-Hodgkin lymphoma. BMC Cancer 10: 517, 2010.

6. Abaan OD and Toretsky JA: PTPL1: A large phosphatase with a split personality. Cancer Metastasis Rev 27: 205-214, 2008

7. Guo H, Zhu P, Yan L, Li R, Hu B, Lian Y, Yan J, Ren X, Lin S, Li J, et al: The DNA methylation landscape of human early embryos. Nature 511: 606-610, 2014.

8. Lübbert M: DNA methylation inhibitors in the treatment of leukemias, myelodysplastic syndromes and hemoglobinopathies: Clinical results and possible mechanisms of action. Curr Top Microbiol Immunol 249: 135-164, 2000.

9. Amara K, Ziadi S, Hachana M, Soltani N, Korbi S and Trimeche M: DNA methyltransferase DNMT3b protein overexpression as a prognostic factor in patients with diffuse large B-cell lymphomas. Cancer Sci 101: 1722-1730, 2010.

10. Bejar R and Steensma DP: Recent developments in myelodysplastic syndromes. Blood 124: 2793-2803, 2014.

11. Freiss G and Chalbos D: PTPN13/PTPL1: An important regulator of tumor aggressiveness. Anticancer Agents Med Chem 11: 78-88, 2011.

12. Herman JG, Graff JR, Myöhänen S, Nelkin BD and Baylin SB: Methylation-specific PCR: A novel PCR assay for methylation status of CpG islands. Proc Natl Acad Sci USA 93: 9821-9826, 1996.

13. Shi H, Guo J, Duff DJ, Rahmatpanah F, Chitima-Matsiga R, Al-Kuhlani M, Taylor KH, Sjahputera O, Andreski M, Wooldridge JE, et al: Discovery of novel epigenetic markers in non-Hodgkin's lymphoma. Carcinogenesis 28: 60-70, 2007.

14. Lossos IS: The DNA methylome: A novel biomarker. Blood 123: $1627-1628,2014$.

15. Bittenbring JT,NeumannF,Altmann B,Achenbach M,Reichrath J, Ziepert M, Geisel J, Regitz E, Held G and Pfreundschuh M: Vitamin D deficiency impairs rituximab-mediated cellular cytotoxicity and outcome of patients with diffuse large B-cell lymphoma treated with but not without rituximab. J Clin Oncol 32: 3242-3248, 2014.

16. Hunter T: The role of tyrosine phosphorylation in cell growth and disease. Harvey Lect 94: 81-119, 1998-1999. 
17. Paz MF, Fraga MF, Avila S, Guo M, Pollan M, Herman JG and Esteller M: A systematic profile of DNA methylation in human cancer cell lines. Cancer Res 63: 1114-1121, 2003.

18. Bodoor K, Haddad Y, Alkhateeb A, Al-Abbadi A, Dowairi M, Magableh A, Bsoul N and Ghabkari A: DNA hypermethylation of cell cycle (p15 and p16) and apoptotic (p14, p53, DAPK and TMS1) genes in peripheral blood of leukemia patients. Asian Pac J Cancer Prev 15: 75-84, 2014

19. Kupčinskaitè-Noreikienè R, Skiecevičienė J, Jonaitis L, Ugenskienè R, Kupčinskas J, Markelis R, Baltrènas V, Sakavičius L, Semakina I, Grižas S, et al: CpG island methylation of the MLH1, MGMT, DAPK, and CASP8 genes in cancerous and adjacent noncancerous stomach tissues. Medicina (Kaunas) 49: 361-366, 2013.

20. Ng HY, Wan TS, So CC and Chim CS: Epigenetic inactivation of DAPK1, p14ARF, mir-34a and $-34 \mathrm{~b} / \mathrm{c}$ in acute promyelocytic leukaemia. J Clin Pathol 67: 626-631, 2014.

21. Hutt DM, Roth DM, Vignaud H, Cullin C and Bouchecareilh M: The histone deacetylase inhibitor, Vorinostat, represses hypoxia inducible factor 1 alpha expression through translational inhibition. PLoS One 9: e106224, 2014.

22. Witzig TE, Hu G, Offer SM, Wellik LE, Han JJ, Stenson MJ, Dogan A, Diasio RB and Gupta M: Epigenetic mechanisms of protein tyrosine phosphatase 6 suppression in diffuse large B-cell lymphoma: Implications for epigenetic therapy. Leukemia 28 : 147-154, 2014.

23. Kroesen M, Gielen P, Brok IC, Armandari I, Hoogerbrugge PM and Adema GJ: HDAC inhibitors and immunotherapy; a double edged sword? Oncotarget 5: 6558-6572, 2014.

24. Jones PA and Baylin SB: The fundamental role of epigenetic events in cancer. Nat Rev Genet 3: 415-428, 2002.

25. Jones PA: Overview of cancer epigenetics. Semin Hematol 42 (Suppl 2): S3-S8, 2005

26. Ying J, Li H, Cui Y, Wong AH, Langford $\mathrm{C}$ and Tao Q: Epigenetic disruption of two proapoptotic genes MAPK10/JNK3 and PTPN13/FAP-1 in multiple lymphomas and carcinomas through hypermethylation of a common bidirectional promoter. Leukemia 20: 1173-1175, 2006.

27. Lee SH, Shin MS, Lee HS, Bae JH, Lee HK, Kim HS, Kim SY, Jang JJ, Joo M, Kang YK, et al: Expression of Fas and Fas-related molecules in human hepatocellular carcinoma. Hum Pathol 32: 250-256, 2001

28. Sripayap P, Nagai T, Uesawa M, Kobayashi H, Tsukahara T, Ohmine K, Muroi K and Ozawa K: Mechanisms of resistance to azacitidine in human leukemia cell lines. Exp Hematol 42: 294-306, 2014
29. Zhou Y and Hu Z: Genome-wide demethylation by 5-aza-2'-deoxycytidine alters the cell fate of stem/progenitor cells. Stem Cell Rev 11: 87-95, 2015

30. Chaudhry P, Srinivasan R and Patel FD: Differential expression of Fas family members and Bcl-2 family members in benign versus malignant epithelial ovarian cancer (EOC) in North Indian population. Mol Cell Biochem 368: 119-126, 2012.

31. Mori S, Murakami-Mori K, Jewett A, Nakamura S and Bonavida B: Resistance of AIDS-associated Kaposi's sarcoma cells to Fas-mediated apoptosis. Cancer Res 56: 1874-1879, 1996.

32. Zhang X, Brunner T, Carter L, Dutton RW, Rogers P, Bradley L, Sato T, Reed JC, Green D and Swain SL: Unequal death in Thelper cell (Th)1 and Th2 effectors: Th1, but not Th2, effectors undergo rapid Fas/FasL-mediated apoptosis. J Exp Med 185: 1837-1849, 1997.

33. Nariai Y, Mishima K, Yoshimura Y and Sekine J: FAP-1 and $\mathrm{NF}-\kappa \mathrm{B}$ expressions in oral squamous cell carcinoma as potential markers for chemo-radio sensitivity and prognosis. Int J Oral Maxillofac Surg 40: 419-426, 2011.

34. Vondrácek J, Sheard MA, KrejcíP, Minksová K, Hofmanová J and Kozubík A: Modulation of death receptor-mediated apoptosis in differentiating human myeloid leukemia HL-60 cells. J Leukoc Biol 69: 794-802, 2001

35. Michor F, Hughes TP, Iwasa Y, Branford S, Shah NP, Sawyers CL and Nowak MA: Dynamics of chronic myeloid leukaemia. Nature 435: 1267-1270, 2005.

36. Arai M, Kannagi M, Matsuoka M, Sato T, Yamamoto N and Fujii M: Expression of FAP-1 (Fas-associated phosphatase) and resistance to Fas-mediated apoptosis in $T$ cell lines derived from human $\mathrm{T}$ cell leukemia virus type 1-associated myelopathy/tropical spastic paraparesis patients. AIDS Res Hum Retroviruses 14: 261-267, 1998

37. Glondu-Lassis M, Dromard M, Lacroix-Triki M, Nirdé P, Puech C, Knani D, Chalbos D and Freiss G: PTPL1/PTPN13 regulates breast cancer cell aggressiveness through direct inactivation of Src kinase. Cancer Res 70: 5116-5126, 2010.

38. He RJ, Yu ZH, Zhang RY and Zhang ZY: Protein tyrosine phosphatases as potential therapeutic targets. Acta Pharmacol Sin 35: 1227-1246, 2014

39. Kamihira S, Yamada Y, Hirakata Y, Tomonaga M, Sugahara K, Hayashi T, Dateki N, Harasawa H and Nakayama K: Aberrant expression of caspase cascade regulatory genes in adult T-cell leukaemia: Survivin is an important determinant for prognosis. Br J Haematol 114: 63-69, 2001. 